\title{
1
}

\section{Introduction: A Framework for Managing Food Waste}

\section{Elina Närvänen, Nina Mesiranta, Malla Mattila and Anna Heikkinen}

\section{The Wicked Problem of Food Waste}

There is an increasing political and scientific consensus about the need to reduce global food waste. In 2015, the United Nations' Sustainable Development Goal 12.3 set the target of "By 2030, halve per capita global food waste at the retail and consumer levels and reduce food losses along production and supply chains, including postharvest losses" (United Nations 2015). This target stems from a broad understanding of the negative consequences of food losses and waste,

E. Närvänen $(\triangle) \cdot$ N. Mesiranta $\cdot$ M. Mattila · A. Heikkinen

Tampere University, Tampere, Finland

e-mail: elina.narvanen@tuni.fi

N. Mesiranta

e-mail: nina.mesiranta@tuni.fi

M. Mattila

e-mail:malla.mattila@tuni.fi
A. Heikkinen
e-mail: anna.l.heikkinen@tuni.fi
(C) The Author(s) 2020 
including the waste of land, water and energy, while causing unnecessary emissions of greenhouse gases. The Food and Agriculture Organization of the United Nations (FAO) has estimated that food losses and waste account for more than $10 \%$ of global energy consumption (FAO 2017). Hence, food waste is a major contributor to climate change. Furthermore, wasting food is a moral concern, since it impacts global food security and increases the gap between affluent and lowincome people. Food produced for human consumption is wasted at the same time as a large part of the global population suffers from hunger and malnutrition. From an economic point of view, inefficiencies accrue from food losses and waste for both organisations such as farms, food manufacturers, retailers and restaurants and households.

Food waste can be characterised as a "wicked problem" (Närvänen et al. 2019), which are defined as unstructured, cross-cutting and relentless (Weber and Khademian 2008; see also Rittel and Webber 1973). We elaborate on these characteristics of food waste as a wicked problem in this introduction for the book Food Waste Management: Solving the Wicked Problem.

Firstly, food waste is an unstructured problem, because its precise causes and effects are difficult to identify, and there is no shared problem definition. Even though there is now a growing body of research focussing on food waste quantification and measurement (see, e.g., Parfitt et al. 2010; Thyberg et al. 2015; Xue et al. 2017; see Hartikainen et al., Chapter 16) as well as its key antecedents (see, e.g., AschemannWitzel et al. 2015; Porpino et al. 2015; Stancu et al. 2016), there is no unified agreement on the definition of food waste. Some definitions take into account both food loss and waste (Buzby et al. 2014; Gustavsson et al. 2011) throughout the food system, while others highlight dimensions such as edibility versus inedibility or avoidability versus unavoidability (see, e.g., Blichfeldt et al. 2015; Papargyropoulou et al. 2014; Katajajuuri et al. 2014).

In this book, we adopt a broad perspective and consider all types of food surplus, loss and waste within the food system. Even though food waste can be defined in various ways, a solution orientation is essential. One approach for evaluating the different types of solutions is the food waste hierarchy. It refers to the order of preference for action 
suggested by governmental bodies and political institutions both in the European Union (EU) (ECA 2016; Papargyropoulou et al. 2014) and in the United States (US) (EPA, n.d.). The primary focus should be on actions that prevent food waste from occurring. The second most preferred measures are those that utilise surplus food or potential food waste for feeding people, that is, mainly food donations. If this is not possible, the next level suggests food waste should be used as an animal feed. The bottom levels, or least preferred actions, relate to recycling food waste into compost or converting it into biogas or biodiesel. The least preferred option is the disposal of food waste into landfills or by incineration.

It must, however, be noted that no solution can solve the whole problem (Weber and Khademian 2008), and, hence, each solution also changes how the problem of food waste is perceived. The solutions for tackling the food waste problem — such as reducing it at the source, distributing it to people in need and reusing it to feed animals_-may also compete with each other (Mourad 2016). For instance, depending on the solution, food waste can be seen as a problem to be addressed, as food or as a resource for further processing. Furthermore, the boundary between food and waste is often negotiable in everyday life, and, hence, for actors attempting to reduce food waste, the phenomenon is always context-bound and dynamic (Mattila et al. 2018b).

Secondly, food waste is also a cross-cutting problem as it involves many stakeholders in the food system from farm to fork (Parfitt et al. 2010). However, according to statistics, in the developed world, food waste occurs mainly at the end of the food chain: by food distribution and especially households (Bräutigam et al. 2014). According to the FAO (Gustavsson et al. 2011), the total estimate of food losses and waste is about one-third of edible food produced, or 1.3 billion tonnes per year. In the developed countries, more than $40 \%$ of food waste emerges at the retail and consumption levels. In developing countries, in contrast, most of the food losses and waste occur in the post-harvest and processing stages. Also, food waste-related scientific research has focussed mainly on the developed countries and downstream food waste, especially on the consumer or household level, but also on retailers, hotels and restaurants (see, e.g., Aschemann-Witzel et al. 2015, 2016; 
Filimonau and Gherbin 2017; Garrone et al. 2014; Graham-Rowe et al. 2014; Papargyropoulou et al. 2016; Parfitt et al. 2010).

Many of the suggested solutions for reducing food waste in the literature have focussed on changing the attitudes and behaviour of individuals (see van Geffen et al., Chapter 2), for example through awareness-raising informational campaigns (for a review, see Aschemann-Witzel et al. 2017; Quested et al. 2013; see Sutinen, Chapter 9). More recently, other types of interventions such as those based on behavioural economics (Wansink 2018; see de VisserAmundson and Kleijnen, Chapter 3) and design thinking or technological innovations (Hebrok and Boks 2017; see Burke and Napawan, Chapter 7; Lake et al., Chapter 8) have been suggested to complement the informational interventions. Some countries, such as South Korea, have even utilised public policy interventions through regulations that are intended to reduce household food waste and increase its recycling. In South Korea, households are now charged based on the food waste they have produced, and regulations have been recently amended to enable converting the resulting food waste with the help of insects into animal feed (Bagherzadeh et al. 2014; Jackson 2018; see Fowles and Nansen, Chapter 12).

In addition to behaviour change, some existing solutions concern organisations' strategies, such as linking food waste reduction with corporate social responsibility (CSR) (see Moser, Chapter 4). Many retailers have in recent years started to voluntarily reduce their food waste by, for instance, donating food to charities and food banks, or redirecting their waste to be used for biofuel production. Furthermore, retailers occupy a critical intermediary position (Welch et al. 2018) and thus can impact their own food waste but also that of other actors, such as farmers and consumers (see Gollnhofer and Boller, Chapter 5; Alhonnoro et al., Chapter 6). Some European countries, such as France and Italy, have also set legal obligations for retailers to donate food (Vaqué 2017). Different policy-level solutions regarding retailer food waste have been identified, including awareness campaigns and changing legislation, norms and standards related to labelling, product standards and food donation (Gruber et al. 2016). 
However, in developing solutions for food waste reduction, it must be acknowledged that even though food distributors and households may produce the greatest amount of (quantifiable) food waste, they should not be held exclusively responsible for its emergence (Evans 2011). Instead, food waste occurs at the intersection of several influences across the food system. These include the myriad ways in which food is, for instance, produced, transported, processed, packaged and stored on the supermarket shelves and at home. For instance, at the consumer level, many routines and contexts influence the emergence of food waste, not only those directly related to the disposal of food (Evans 2014). Various value trade-offs characterise food waste as a wicked problem-actors must often balance between different societal values (Cappellini 2009; Cappellini and Parsons 2012; Evans 2012a, b; Devin and Richards 2018; Welch et al. 2018). The ethical values and principles connected with food waste that influence actors' perceptions of the problem have a significant impact on the suggested solutions and how they are mobilised by actors (see Uusitalo and Takala, Chapter 10; Raippalinna, Chapter 11).

Finally, food waste represents a relentless problem, which cannot be solved once and for all (Weber and Khademian 2008). Wicked problems require various actors to be engaged in solving them through different activities and at different levels. In addition to the aforementioned political momentum, both private and public as well as third sector organisations are involved in innovating solutions for the problem of food waste (see Kowalczyk et al., Chapter 13; Féret, Chapter 15). The food bank system, distributing surplus food from retailers to those in need, has existed for decades and operates globally through different formats. However, traditionally it has been organised by the third sector and has not aimed directly at reducing food waste but rather at solving food insecurity (Galli et al. 2019; Lohnes and Wilson 2018). In recent years, food waste reduction has started to generate interest in the business sphere as well. Food waste reduction and prevention has generated various opportunities for new innovations. ReFED (2018)—a multistakeholder non-profit dedicated to reducing food waste in the UShas reported that in the US alone, more than $\$ 125$ million venture capital and private equity funding was invested in food waste start-ups 
during the 10 first months of 2018. In Europe, the Food Waste Innovation Network (FoodWIN) — an online platform for food waste innovators and entrepreneurs established in 2014-has over $200 \mathrm{mem}$ bers around Europe that work in the domain of food waste (FoodWIN, n.d.). In the US, ReFED currently lists over 400 non-profit and forprofit organisations throughout the US in their innovator database.

Many of the new business models that operate in the field of food waste prevention and reduction are based on utilising the benefits of digitalisation and the platform economy (Mattila et al. 2018a; see de Almeida Oroski, Chapter 14). Furthermore, often the new innovations question and renew the institutional elements, such as norms, symbols and practices, related to food waste emergence (Baron et al. 2018). Also, a "community" perspective has been adopted, wherein food banks and social supermarkets are perceived as key actors in reducing food waste (Michelini et al. 2018).

This book applies diverse perspectives to reducing food waste (see Fig. 1.1). The chapters in Part I focus on the level of individual actors and how their behaviour can be changed to address the problem. The chapters in Part II focus more on how actors and activities are

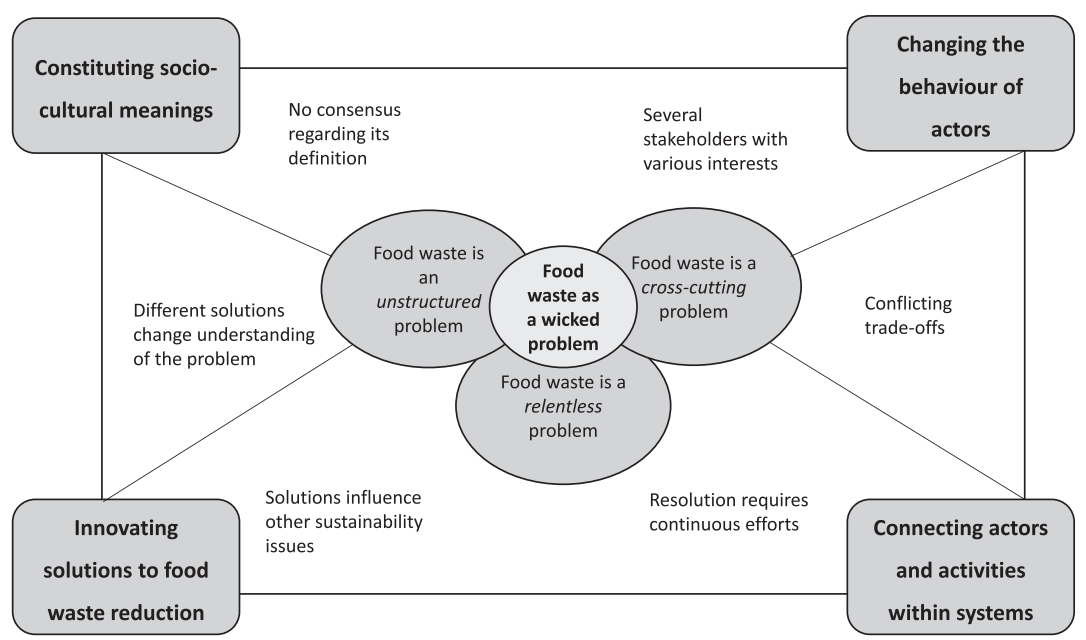

Fig. 1.1 Framework for solving the wicked problem of food waste 
connected at the system level-how food waste reduction is diffused and enacted within different social and material contexts. The chapters in Part III highlight the different sociocultural discourses framing food waste reduction efforts, especially in the media. Furthermore, the chapters in the book's final section, Part IV, introduce cross-cutting cases of food waste reduction.

The book is a multidisciplinary project, combining research from the social sciences including business studies, consumer research, marketing, media studies, design thinking and environmental research. What is common to the chapters of the book is a strong focus on the solutions needed to reduce and prevent food waste. In the book, food waste management is perceived as a multilevel, multi-actor effort to prevent and reduce food waste through various solutions. In our view, it may include, for instance, enacting food management skills at households, stores and restaurants, managing supply and demand for food at all levels and, finally, managing what happens after food becomes inedible to humans. Hence, it is not only a technical solution related to handling waste. As the framework illustrates, food waste management requires shared responsibility of all actors at multiple levels from everyday life to policy level.

\section{Managing Food Waste Reduction-Introducing the Book's Chapters}

\section{Part I-Changing the Behaviour of Actors at the Distribution and Consumption Levels}

The first part of the book addresses the practices and strategies for reducing food waste in households, supermarkets and professional kitchens. Since retailers and consumers have been identified in many studies as producing the most food waste, the majority of previous academic food waste research concerns these actors. The perspective of behavioural change is interested in questions such as: How can people's food waste-related behaviours be changed? What kinds of interventions 
are most effective? What kinds of everyday practices prevent food waste and how can these practices be encouraged?

Studies focussing on consumer food waste have drawn broadly from two different perspectives: individual and societal (see also Hebrok and Boks 2017). Within the individual perspective, consumers decisionmaking processes, motivations, attitudes and behaviours have been studied extensively, utilising, for instance, the theory of planned behaviour (TPB) (Block et al. 2016; Graham-Rowe et al. 2015). Studies have called for informational campaigns and interventions to change the behaviour of individual consumers (for a review, see Hebrok and Boks 2017). However, it has also been argued that informational campaigns on their own are not very effective, and many different kinds of interventions, including those that target both the antecedents and the consequences of food waste behaviour, are needed (Stöckli et al. 2018). In addition, positive meanings related to food waste reduction, such as creativity and aesthetics, have been suggested as beneficial especially in social media campaigns (Närvänen et al. 2018b).

Secondly, the societal perspective to food waste reduction has drawn from sociology and criticised some of the basic assumptions involved in the individual perspective (Evans 2012a; Southerton and Yates 2015). These include questioning the ability of changes in attitude to impact people's behaviour. Food waste is not a behaviour that people perform intentionally. Rather, it is the consequence of a variety of everyday life practices taking place in social and material contexts that influence how people act (Evans 2011). Many studies have drawn from the practice-theoretical view-analysing the ways in which food waste can be reduced by changing the elements of everyday practices such as materials, meanings and competences (Närvänen et al. 2013, 2016; Mattila et al. 2018b; Hebrok and Heidenstrøm 2019). Furthermore, the societal perspective draws attention to the active agency of people in reducing food waste. Consumers may be perceived as active agents rather than passive targets of initiatives such as educational campaigns (Närvänen et al. 2018a). Examples of active consumer-citizenship initiatives and movements include freegans or dumpster divers (Gollnhofer 2017), volunteer "foodsavers" (Schanes and Stagl 2019) and food bloggers (Närvänen et al. 2013). The individual and societal perspectives 
have so far remained quite separate, even though they complement each other and could provide new insights on driving sustainable change at the level of individual actors.

In Chapter 2, Lisanne van Geffen, Erica van Herpen and Hans van Trijp build an integrative review of the existing literature to evaluate the drivers and constraints for behavioural change to reduce consumer food waste. The aim of the chapter is to offer suggestions and guidelines for interventions to prevent behaviours that lead to food waste. Van Geffen et al. encourage practitioners to focus on two kinds of interventions: those that focus on goal setting and those that focus on goal striving. In Chapter 3, Anna de Visser-Amundson and Mirella Kleijnen study nudging as a strategy for food waste reduction in professional kitchens and the significance of pre-commitment and setting of social norms to promote the behavioural change of employees. They argue that costefficiency and waste prevention can be compatible goals while still providing service excellence. The empirical results demonstrate that changing the choice architecture at the professional kitchens has an impact on food waste. In Chapter 4, Christine Moser builds on practice theory and discusses managers' food waste reduction practices in supermarkets. She illustrates how supermarket managers enact a set of practices to reduce food waste in order to engage in micro-level CSR. Moser's analysis identifies the practices of monitoring food waste, sharing knowledge and collaborating with external stakeholders as relevant in attempting to reduce supermarket food waste. The chapter also contains practical suggestions for managing food waste at the retail level.

\section{Part II-Connecting Actors and Activities Within Systems}

The second part of the book focusses on the interconnections of actors and activities while making the effort to reduce food waste. This part is interested in questions such as: How are different actors in the food system connected with each other? How do these relations and interdependencies help in understanding food waste reduction at the systems level? How can different perspectives be combined to create crossdisciplinary insight and innovative solutions? 
Food waste studies have recognised the need to analyse the food system as a whole instead of focussing only on single predefined actors (see, e.g., Garrone et al. 2014; Göbel et al. 2015; Halloran et al. 2014; Parfitt et al. 2010). However, often the linear metaphor of a "food chain" is used to describe how food waste emerges at different stages of food production and consumption. Food waste does not always emerge in this linear way: the root causes of, for example, retailer and consumer food waste may lie elsewhere in the system (Alexander et al. 2013). Furthermore, the power relations between different actors, such as farmers and retailers, influence food waste: while retailers claim to reduce food waste, their standards create it elsewhere in the system (Devin and Richards 2018). On the other hand, actors may also facilitate other actors' food waste reduction, such as when retailers improve the packaging, pricing strategies and communications targeted at consumers in order to affect a change in household food waste (Aschemann-Witzel et al. 2016).

These interdependencies and complex relations between the actors and activities in the food system are seldom identified. Exceptions to this include studies that have addressed global and intersectoral connections in food waste reduction by adopting a food systems approach (Galli et al. 2019), food waste regime approach (Gille 2012) and service ecosystem perspective (Baron et al. 2018). These studies highlight that in order to accomplish systemic change towards sustainability, institutional structures need to be disrupted. Technological innovations or isolated, stand-alone solutions will not be enough to accomplish systemic change. The chapters of this section of the book discuss the interdependencies of actors and activities in the food (waste) system from various perspectives, including the public/private, visible/invisible and human/non-human.

In Chapter 5, Johanna Gollnhofer and Daniel Boller show how the business practice of selling ugly fruit has its roots in the German anti-food waste movement and activism. After dumpster divers had increased the awareness of retail food waste, food-sharing organisations started to collaborate with retailers. Finally, retailers started to monetise these anti-food waste practices by selling ugly fruit and vegetables. 
The chapter shows how the seemingly distinct interests of actors can co-evolve in the quest to solve systemic challenges.

In addition to acknowledging human actors and their interconnected relationships, some studies have emphasised the critical role of various objects and materials in the wicked problem of food waste, such as domestic technologies, foodstuffs and food containers (Evans 2018; Waitt and Phillips 2016; Watson and Meah 2012; Mattila et al. 2018b; Hebrok and Heidenstrøm 2019). These studies posit that food and waste are to be considered lively (more-than-human) matters. As such, they contain negotiable boundaries and, consequently, ephemeral "becomings". Thus, the studies argue that transformations of food into waste and ways to mitigate these occurrences need to be understood in relation to multiple, continual and complex movements among various interconnected human and non-human actors.

Recently, this metaphorical systems view has been extended to a retail setting (Midgley 2019). In Chapter 6, Lotta Alhonnoro, Hanna Leipämaa-Leskinen and Henna Syrjälä present a novel approach to the issue by focussing on the interactions of various heterogeneous actors in a supermarket's bread and bakery section, and how they may-or may not - generate food waste. The study shows that employees' everyday working practices involve several situations and activities in which multiple human and non-human actors together engage in negotiating and setting boundaries between saleable and non-saleable bread and bakery products and, further, between food and waste. Without giving careful attention to various materials, the many ways to influence food waste reduction in the retail setting may be ignored.

The following two chapters in this part move from focussing on a single site such as a retailer to analysing how practices traditionally perceived to take place in one site, such as the home, are actually connected to larger systems, such as the sewer system. Both Chapters 7 and 8 criticise the ability of stand-alone techno-scientific interventions to solve the wicked problem of food waste.

In Chapter 7, Ellen Burke and N. Claire Napawan assess the role of environmental design in addressing food waste and suggest a socioecological approach to environmental design to create effective solutions to food waste. They utilise different approaches: urban metabolism, 
community resilience and participatory design as well as ecofeminism to discuss the case of \#FOGWASTE - a project commissioned by the City of San Jose, California, in the US-educating and activating citizens in the context of liquid food waste (fats, oils and grease). Burke and Napawan argue for a more fluid approach to environmental design where the interdependence of domestic practices, urban infrastructure and natural systems is recognised.

In Chapter 8, Danielle Lake, Amy McFarland and Jody Vogelzang discuss how systems thinking and design thinking can be combined to develop interventions to reduce food waste. Drawing insights from these approaches, the authors suggest ten strategies for change agents (e.g. activists, policymakers, purchasing agents and restaurant managers) to plan and implement resilient interventions. The authors illustrate these strategies by analysing a case of a transdisciplinary living lab, "Wealth from Waste", in two universities in Sydney, Australia. In the case, the students, faculty members and industry representatives were invited to co-create interventions that fit the proposed strategies. All in all, the authors argue for solutions that are transdisciplinary, holistic and systematic.

\section{Part III-Constituting Sociocultural Meanings}

The third part of the book presents a sociocultural view of food waste reduction. The view directs attention to the various meanings, understandings, discourses and values that are constructed, maintained and reconstructed in the society. These sociocultural meanings of food waste allow for understanding how the issue is interlinked with the development of the society. Consequently, the sociocultural view is interested in questions such as: How do the meanings of food waste evolve and vary? Why, in different spatial and temporal contexts, might food waste be seen as a key challenge for humanity, a business opportunity or a non-issue? What are the consequences of such views?

The sociocultural view is grounded in the linguistic turn originating from social sciences and in social constructionism (Berger and Luckmann 1966). According to the social constructionist tradition, 
social reality is created and maintained by humans in social interactions. Furthermore, social activity is seen as a linguistic and discursive process constructing social phenomena with material consequences (Burr 1995; Crotty 1998). The particular appeal of focussing on language use and accepting the material consequences of such activity is that this approach, basically, offers possibilities for understanding the origins of and motivations for actions (Heikkinen et al. 2017; Joutsenvirta 2009). This approach also allows for the intended and unintended consequences of language use to be scrutinised. Thus, the research interest becomes located on how certain ways of talking about and understanding food waste may facilitate or hinder the efforts of steering corporate or consumer behaviour (Evans et al. 2012; Joutsenvirta 2009). To sum up, the sociocultural view of food waste builds on two focal notions. First, language is not a transparent medium to "reality"; rather, language constructs, maintains and recreates social realities. Second, meanings and discourses are viewed as constituting and being constituted by the social and cultural norms, values and habits related to practices of food waste reduction.

Previous research on food waste utilising the sociocultural perspective has been scattered among different disciplines, such as sociology, marketing and consumer research, management and organisation studies and environmental policy research (for a discussion, see Evans et al. 2012). Culturally and linguistically oriented food waste literature has examined, firstly, how food waste can be defined. This means studying how the edibility or inedibility of food is culturally and socially constructed; that is, how food is re-conceptualised as waste (Blichfeldt et al. 2015; Brunori et al. 2013; Campbell et al. 2017; Evans 2011, 2012b; Evans et al. 2012; Thompson and Haigh 2017). Secondly, and building on the first point, attention has been paid to the consequences and significance of food waste understandings. This approach seeks to explicate the sociocultural-including the political, economic and ideologicalrelationships in which food waste is embedded (Evans et al. 2012). In research, this means asking how the ways of talking about and understanding food waste are linked to the actions of individuals, groups, organisations and society at large (Närvänen et al. 2016). While there has been increased attention on the sociocultural view of food waste, 
research is still limited in understanding how societal actors, media, marketing professionals, managers and consumers, among others, describe and explain the issues of food waste and food waste reduction. The three articles in this book make an insightful contribution to this area of research.

The third part of the book consists of three chapters that examine the sociocultural meanings of food waste in different texts. The sociocultural view brings forth the non-places along with the places, such as supermarkets and households, where food waste meanings are constructed. Previous research on non-places has examined, for instance, reality television programmes (Thompson and Haigh 2017) and public discourse taking place in the entertainment media, popular press and news media (Frye and Fox 2015). In this part, the focus is particularly on non-places, such as consumer educational campaign material and media texts.

In Chapter 9, Ulla-Maija Sutinen examines what kinds of assumptions about consumers are constructed in the visual material of food waste campaigns. This chapter builds on the social marketing and consumer behaviour change literatures and utilises semiotic analysis to explicate the visual materials of 14 food waste campaigns organised in Finland and Sweden. Sutinen presents six assumptions about consumers reflecting the assumed orientation and agency of consumers. The chapters suggest that currently the cognitive approach emphasising the rationality of consumers prevails in the campaigns and that change in consumer behaviour can be advanced by constructing campaigns that also utilise affective, conative and sociocultural approaches.

Food waste meanings are often discussed in relation to the ethical, moral and value-laden aspects of food waste (Thompson and Haigh 2017), CSR and power (Devin and Richards 2018). Chapter 10 by Outi Uusitalo and Tuomo Takala focusses on the societal values, virtues and practices that foster food waste reduction. The chapter sheds light on the so far scarcely researched socio-philosophical and ethical issues underlying food waste behaviour in the food chain. Uusitalo and Takala analyse Finnish media texts and show how virtues related to food waste practices have manifested themselves in agrarian (1885-1917) and mature consumer society (2008-2017). This chapter highlights how 
ethical principles can underpin our understanding of food waste and how food chain actors' virtues can guide practices towards more sustainable ways of handling excess food.

Another focal topic related to the sociocultural approach is the responsibilisation and mobilisation of consumers (Evans et al. 2017). Continuing with a focus on Finnish media texts, Chapter 11 by LiiaMaria Raippalinna analyses how consumers are mobilised for food waste reduction in media discourse. The chapter builds on governmentality studies and practice theoretical approach to sustainable consumption. By using critical discourse analysis, Raippalinna analyses the discursive construction of food waste and consumers in the leading Finnish newspaper during 2010-2017. The findings present three discourses of consumer mobilisation: scientific-political discourse, home economics discourse and the discourse of new urban food culture. Raippalinna argues that any transformation of consumer food waste practices requires that media discourse integrates and normalises food waste prevention and reduction as a part of all media discourses and genres.

\section{Part IV-Innovating Practical Solutions}

The fourth and final part of this book includes five chapters showcasing various types of practical solutions and innovations to food waste reduction and prevention. In Chapter 12, Trevor M. Fowles and Christian Nansen discuss how utilising various insects to process food wastethat is, insect-based bioconversion-can provide a solution to turn food waste into valuable materials. This process-offering viable business opportunities as well-allows food waste to be converted into animal feed and food for people as well as into secondary industrial compounds such as biofuel or pharmaceuticals. After conversion, the leftover waste can be further used, for example, as a soil amendment. Even though not encouraging prevention of food waste per se, insect-based bioconversion is an example of a solution that diverts food waste back into different levels of the food waste hierarchy.

In Chapter 13, Christine Kowalczyk, Brian J. Taillon and Laura Hearn present another opportunity for waste reduction in the often 
neglected farming industry where food waste has become a problem, also creating economic losses for farmers. In their article, they discuss the benefits of gleaning - recovering farm produce left behind after harvesting due to, for example, strict cosmetic standards-and how the challenges of a more traditional gleaning model (where volunteers glean farm produce for charities and food banks) can be overcome through introducing a gleaning business model.

To continue with solutions that are enabled more by technology, in Chapter 14, Fabio de Almeida Oroski analyses the business models of various applications designed to sell or donate surplus food on digital platforms. As reusing surplus food for human consumption is often a race against time (before the food becomes unfit for humans), digital platforms bring together and can facilitate transactions between those actors with a supply of surplus food (e.g. restaurants, retailers and consumers) and those that require surplus food (e.g. food banks and charities). As de Almeida Oroski illustrates, digital platforms and applications can be beneficial for both non-profit and for-profit organisations.

The final two chapters in the fourth part concentrate on implementing food reduction and prevention policies in practice. In Chapter 15, Samuel Féret discusses the EU-funded ECOWASTE4FOOD project through which local and regional authorities from seven EU countries collaborate by sharing and exchanging experiences on food wastereducing innovations in their regions. As a result of this and local stakeholder collaboration, the project helps the partners in designing action plans for their regions in order to comply with food reduction policy targets set by the EU. In his article, Féret introduces examples from various regions and from various levels of the food waste hierarchy, including also those preventing food waste.

In Chapter 16, Hanna Hartikainen, Inkeri Riipi, Juha-Matti Katajajuuri and Kirsi Silvennoinen, on the other hand, focus on the approaches to and challenges of implementing EU food waste measurement and monitoring in practice. They discuss how this EU-level policy can best be implemented for monitoring food waste in various parts of the food chain in Finland, but also how monitoring quantities of food waste helps to direct action for food waste reduction. 


\section{Conclusions}

Food waste research has gradually moved from focussing on understanding the phenomenon and measuring it towards less actor-centric, more holistic approaches. This book represents this development as it combines research from multiple fields and a variety of theoretical perspectives, as well as provides practical insights about the issue.

Since food waste is a wicked problem, it is important to adopt a holistic view. The chapters of this book discuss different levels where change is needed: actors, systems and sociocultural and institutional structures. This introductory chapter introduces a framework that incorporates the chapters and their relations to each other in solving the wicked problem of food waste. Accordingly, it highlights the need for interconnected, multilevel solutions that go beyond single actors and activities within predefined silos of the food system. Furthermore, even though food waste can be perceived as a resource, the solutions (such as conversion to biogas) should not increase the demand for food waste. Instead, preferable solutions should create incentives to prevent it from emerging. The framework also operates as a platform for future research related to food waste, hopefully inspiring researchers to adopt new avenues focussed on ensuring its prevention.

In addition to the solutions provided by this book, we argue that solving the wicked problem of food waste will require both incentives and sanctions. Reducing and preventing food waste needs to be considered as positive - on the assumption that appeals to guilt seldom spur action. However, remaining at the level of individual actors will not be sufficient as the impactful solutions may lie elsewhere than where the food waste occurs. Furthermore, there needs to be regulatory pressure to sanction behaviours leading to food waste as, despite being aware of the problem, actors might not own the problem.

In managing food waste, we need active change agents to develop and implement solutions at different levels of the food system as well as more holistically between systems. The current food system faces a variety of wicked problems, of which food waste is just one. A sustainable future requires the critical evaluation and transformation of the food system as a whole. We hope that this book will provide research-based 
insights and solutions for these change agents and inspire them to act as well as mobilise others in the quest to battle against the wicked problem of food waste.

\section{References}

Alexander, C., Gregson, N., \& Gille, Z. (2013). Food waste. In A. Murcott, W. Belasco, \& P. Jackson (Eds.), The handbook of food research (pp. 471484). London: Bloomsbury.

Aschemann-Witzel, J., De Hooge, I., Amani, P., Bech-Larsen, T., \& Oostindjer, M. (2015). Consumer-related food waste: Causes and potential for action. Sustainability, 7(6), 6457-6477.

Aschemann-Witzel, J., De Hooge, I., \& Normann, A. (2016). Consumerrelated food waste: Role of food marketing and retailers and potential for action. Journal of International Food \& Agribusiness Marketing, 28(3), 271-285.

Aschemann-Witzel, J., De Hooge, I. E., Rohm, H., Normann, A., Bossle, M. B., Grønhøj, A., et al. (2017). Key characteristics and success factors of supply chain initiatives tackling consumer-related food waste-A multiple case study. Journal of Cleaner Production, 155, 33-45.

Bagherzadeh, M., Inamura, M., \& Jeong, H. (2014). Food waste along the food chain. OECD Food, Agriculture and Fisheries Papers, No. 71. Paris: OECD Publishing. http://dx.doi.org/10.1787/5jxrcmftzj36-en. Accessed on 19.3.2019.

Baron, S., Patterson, A., Maull, R., \& Warnaby, G. (2018). Feed people first: A service ecosystem perspective on innovative food waste reduction. Journal of Service Research, 21(1), 135-150.

Berger, P. L., \& Luckmann, T. (1966). The social construction of reality: A treatise in the sociology of knowledge. Garden City, NY: Doubleday.

Blichfeldt, B. S., Mikkelsen, M., \& Gram, M. (2015). When it stops being food: The edibility, ideology, procrastination, objectification and internalization of household food waste. Food, Culture \& Society, 18(1), 89-105.

Block, L. G., Keller, P. A., Vallen, B., Williamson, S., Birau, M. M., Grinstein, A., et al. (2016). The squander sequence: Understanding food waste at each stage of the consumer decision-making process. Journal of Public Policy \& Marketing, 35(2), 292-304. 
Bräutigam, K. R., Jörissen, J., \& Priefer, C. (2014). The extent of food waste generation across EU-27: Different calculation methods and the reliability of their results. Waste Management and Research, 32(8), 683-694.

Brunori, G., Malandrin, V., \& Rossi, A. (2013). Trade-off or convergence? The role of food security in the evolution of food discourse in Italy. Journal of Rural Studies, 29, 19-29.

Burr, V. (1995). An introduction to social constructionism. London: Routledge.

Buzby, J. C., Farah-Wells, H., \& Hyman, J. (2014). The estimated amount, value, and calories of postharvest food losses at the retail and consumer levels in the United States. EIB-121. United States Department of Agriculture, Economic Research Service, Economic Information Bulletin Number 112. http://www.ers.usda.gov/webdocs/publications/43833/43680_eib121.pdf. Accessed on 26.2.2019.

Campbell, H., Evans, D., \& Murcott, A. (2017). Measurability, austerity and edibility: Introducing waste into food regime theory. Journal of Rural Studies, 51, 168-177.

Cappellini, B. (2009). The sacrifice of re-use: The travels of leftovers and family relations. Journal of Consumer Behaviour, 8(6), 365-375.

Cappellini, B., \& Parsons, E. (2012). Practising thrift at dinnertime: Mealtime leftovers, sacrifice and family membership. The Sociological Review, 60, $121-134$.

Crotty, M. (1998). The foundations of social research: Meaning and perspective in the research process. London: Sage.

Devin, B., \& Richards, C. (2018). Food waste, power, and corporate social responsibility in the Australian food supply chain. Journal of Business Ethics, 150(1), 199-210.

ECA. (2016). Combating food waste: An opportunity for the EU to improve the resource-efficiency of the food supply chain. European Court of Auditors. Special report no 34/2016. Luxembourg: Publications Office of the European Union. https://www.eca.europa.eu/Lists/ECADocuments/SR16_ 34/SR_FOOD_WASTE_EN.pdf. Accessed on 22.2.2019.

EPA. (n.d.). Food recovery hierarchy. United States Environmental Protection Agency. https://www.epa.gov/sustainable-management-food/food-recoveryhierarchy. Accessed on 22.2.2019.

Evans, D. (2011). Blaming the consumer-Once again: The social and material contexts of everyday food waste practices in some English households. Critical Public Health, 21(4), 429-440. 
Evans, D. (2012a). Beyond the throwaway society: Ordinary domestic practice and a sociological approach to household food waste. Sociology, 46(1), 41-56.

Evans, D. (2012b). Binning, gifting and recovery: The conduits of disposal in household food consumption. Environment and Planning D: Society and Space, 30(6), 1123-1137.

Evans, D. (2014). Food waste: Home consumption, material culture and everyday life. London: Bloomsbury.

Evans, D. M. (2018). Rethinking material cultures of sustainability: Commodity consumption, cultural biographies and following the thing. Transactions of the Institute of British Geographers, 43(1), 110-121.

Evans, D., Campbell, H., \& Murcott, A. (2012). A brief pre-history of food waste and the social sciences. The Sociological Review, 60(2_suppl), 5-26.

Evans, D., Welch, D., \& Swaffield, J. (2017). Constructing and mobilizing 'the consumer': Responsibility, consumption and the politics of sustainability. Environment and Planning A: Economy and Space, 49(6), 1396-1412.

FAO. (2017). The future of food and agriculture-Trends and challenges. Food and Agriculture Organization of the United Nations. http://www.fao.org/3/ a-i6583e.pdf. Accessed on 26.2.2019.

Filimonau, V., \& Gherbin, A. (2017). An exploratory study of food waste management practices in the UK grocery retail sector. Journal of Cleaner Production, 167, 1184-1194.

FoodWIN. (n.d.). Network. https://foodwin.org/network/. Accessed on 22.2.2019.

Frye, J., \& Fox, R. (2015). The rhetorical construction of food waste in US public discourse. Food Studies: An Interdisciplinary Journal, 5(4), 43-57.

Galli, F., Cavicchi, A., \& Brunori, G. (2019). Food waste reduction and food poverty alleviation: A system dynamics conceptual model. Agriculture and Human Values. https://doi.org/10.1007/s10460-019-09919-0.

Garrone, P., Melacini, M., \& Perego, A. (2014). Opening the black box of food waste reduction. Food Policy, 46, 129-139.

Gille, Z. (2012). From risk to waste: Global food waste regimes. The Sociological Review, 60(2_suppl), 27-46.

Göbel, C., Langen, N., Blumenthal, A., Teitscheid, P., \& Ritter, G. (2015). Cutting food waste through cooperation along the food supply chain. Sustainability, 7(2), 1429-1445.

Gollnhofer, J. F. (2017). The legitimation of a sustainable practice through dialectical adaptation in the marketplace. Journal of Public Policy \& Marketing, 36(1), 156-168. 
Graham-Rowe, E., Jessop, D. C., \& Sparks, P. (2014). Identifying motivations and barriers to minimising household food waste. Resources, Conservation and Recycling, 84, 15-23.

Graham-Rowe, E., Jessop, D. C., \& Sparks, P. (2015). Predicting household food waste reduction using an extended theory of planned behaviour. Resources, Conservation and Recycling, 101, 194-202.

Gruber, V., Holweg, C., \& Teller, C. (2016). What a waste! Exploring the human reality of food waste from the store manager's perspective. Journal of Public Policy \& Marketing, 35(1), 3-25.

Gustavsson, J., Cederberg, C., Sonesson, U., Van Otterdijk, R., \& Meybeck, A. (2011). Global food losses and food waste-Extent, causes and prevention. Rome: FAO. http://www.fao.org/3/a-i2697e.pdf. Accessed on 26.2.2019.

Halloran, A., Clement, J., Kornum, N., Bucatariu, C., \& Magid, J. (2014). Addressing food waste reduction in Denmark. Food Policy, 49, 294-301.

Hebrok, M., \& Boks, C. (2017). Household food waste: Drivers and potential intervention points for design-An extensive review. Journal of Cleaner Production, 151, 380-392.

Hebrok, M., \& Heidenstrøm, N. (2019). Contextualising food waste prevention-Decisive moments within everyday practices. Journal of Cleaner Production, 210, 1435-1448.

Heikkinen, A., Kujala, J., Laine, M., \& Mäkelä, H. (2017). Discourse analysis as a method for business ethics and corporate responsibility research. In P. H. Werhane, E. Freeman, \& S. Dmytriyev (Eds.), Cambridge handbook of research approaches to business ethics and corporate responsibility (pp. 138153). Cambridge: Cambridge University Press.

Jackson, B. (2018). Don't waste that banchan: Where South Korea's food waste goes. Korea Exposé. https://www.koreaexpose.com/banchan-south-koreafood-waste/. Accessed on 18.3.2019.

Joutsenvirta, M. (2009). A language perspective to environmental management and corporate responsibility. Business Strategy and the Environment, $18(4), 240-253$.

Katajajuuri, J. M., Silvennoinen, K., Hartikainen, H., Heikkilä, L., \& Reinikainen, A. (2014). Food waste in the Finnish food chain. Journal of Cleaner Production, 73, 322-329.

Lohnes, J., \& Wilson, B. (2018). Bailing out the food banks? Hunger relief, food waste, and crisis in Central Appalachia. Environment and Planning A: Economy and Space, 50(2), 350-369.

Mattila, M., Mesiranta, N., Heikkinen, A., \& Turunen, S. (2018a). Creating value from food waste: Case ResQ Club. In A. K. Dey \& T. Thatchenkery 
(Eds.), Advances in social change leadership \& organizational decision making (pp. 13-22). New Delhi: Bloomsbury Publishing India.

Mattila, M., Mesiranta, N., Närvänen, E., Koskinen, O., \& Sutinen, U. M. (2018b). Dances with potential food waste: Organising temporality in food waste reduction practices. Time \& Society. https://doi.org/10.1177/09614 63X18784123.

Michelini, L., Principato, L., \& Iasevoli, G. (2018). Understanding food sharing models to tackle sustainability challenges. Ecological Economics, 145, 205-217.

Midgley, J. L. (2019). Anticipatory practice and the making of surplus food. Geoforum, 99, 181-189.

Mourad, M. (2016). Recycling, recovering and preventing "food waste": Competing solutions for food systems sustainability in the United States and France. Journal of Cleaner Production, 126, 461-477.

Närvänen, E., Mattila, M., \& Mesiranta, N. (2019). Consumer-citizens as leaders of change: Case food waste. In A. Kangas, J. Kujala, A. Heikkinen, A. Lönnqvist, H. Laihonen, \& J. Bethwaite (Eds.), Leading change in a complex world: Transdisciplinary perspectives (pp. 263-280). Tampere: Tampere University Press.

Närvänen, E., Mesiranta, N., \& Hukkanen, A. (2013). From waste to delicacy: Collective innovation in food disposition practices through blogging. Advances in Consumer Research, 41, 316-320.

Närvänen, E., Mesiranta, N., \& Hukkanen, A. (2016). The quest for an empty fridge. In B. Cappellini, D. Marshall, \& E. Parsons (Eds.), The practice of the meal: Food, families and the market place (pp. 208-219). Abingdon: Routledge.

Närvänen, E., Mesiranta, N., \& Mattila, M. (2018a). Roles of consumer-citizens in food waste reduction. Kulutustutkimus. Nyt, 12(1-2), 20-32.

Närvänen, E., Mesiranta, N., Sutinen, U., \& Mattila, M. (2018b). Creativity, aesthetics and ethics of food waste in social media campaigns. Journal of Cleaner Production, 195, 102-110.

Papargyropoulou, E., Lozano, R., Steinberger, J. K., Wright, N., \& bin Ujang, Z. (2014). The food waste hierarchy as a framework for the management of food surplus and food waste. Journal of Cleaner Production, 76, 106-115.

Papargyropoulou, E., Wright, N., Lozano, R., Steinberger, J., Padfield, R., \& Ujang, Z. (2016). Conceptual framework for the study of food waste generation and prevention in the hospitality sector. Waste Management, 49 , 326-336. 
Parfitt, J., Barthel, M., \& Macnaughton, S. (2010). Food waste within food supply chains: Quantification and potential for change to 2050. Philosophical Transactions of the Royal Society B: Biological Sciences, 365(1554), 3065-3081.

Porpino, G., Parente, J., \& Wansink, B. (2015). Food waste paradox: Antecedents of food disposal in low income households. International Journal of Consumer Studies, 39(6), 619-629.

Quested, T. E., Marsh, E., Stunell, D., \& Parry, A. D. (2013). Spaghetti soup: The complex world of food waste behaviours. Resources, Conservation and Recycling, 79, 43-51.

ReFED. (2018). 2018 U.S. food waste investment report: Trends in private, public, and philanthropic capital. https://www.refed.com/downloads/ReFED2018-US-Food-Waste-Investment-Report.pdf. Accessed on 22.2.2019.

Rittel, H. W., \& Webber, M. M. (1973). Dilemmas in a general theory of planning. Policy Sciences, 4(2), 155-169.

Schanes, K., \& Stagl, S. (2019). Food waste fighters: What motivates people to engage in food sharing? Journal of Cleaner Production, 211, 1491-1501.

Southerton, D., \& Yates, L. (2015). Exploring food waste through the lens of social practice theories: Some reflections on eating as a compound practice. In K. M. Ekström (Ed.), Waste management and sustainable consumption: Reflections on consumer waste (pp. 133-149). London: Routledge.

Stancu, V., Haugaard, P., \& Lähteenmäki, L. (2016). Determinants of consumer food waste behaviour: Two routes to food waste. Appetite, 96, 7-17.

Stöckli, S., Niklaus, E., \& Dorn, M. (2018). Call for testing interventions to prevent consumer food waste. Resources, Conservation and Recycling, 136, 445-462.

Thompson, K., \& Haigh, L. (2017). Representations of food waste in reality food television: An exploratory analysis of Ramsay's Kitchen Nightmares. Sustainability, 9(7), 1139. https://doi.org/10.3390/su9071139.

Thyberg, K. L., Tonjes, D. J., \& Gurevitch, J. (2015). Quantification of food waste disposal in the United States: A meta-analysis. Environmental Science and Technology, 49(24), 13946-13953.

United Nations. (2015). Resolution adopted by the General Assembly on 25 September 2015. A/RES/70/1. http://www.un.org/ga/search/view_doc.asp? symbol=A/RES/70/1\&Lang=E. Accessed on 26.2.2019.

Vaqué, L. G. (2017). French and Italian food waste legislation: An example for other EU member states to follow? European Food and Feed Law Review, 12(3), 224-233. 
Waitt, G., \& Phillips, C. (2016). Food waste and domestic refrigeration: A visceral and material approach. Social and Cultural Geography, 17(3), 359-379. Wansink, B. (2018). Household food waste solutions for behavioral economists and marketers. Journal of Food Products Marketing, 24(5), 500-521.

Watson, M., \& Meah, A. (2012). Food, waste and safety: Negotiating conflicting social anxieties into the practices of domestic provisioning. The Sociological Review, 60, 102-120.

Weber, E. P., \& Khademian, A. M. (2008). Wicked problems, knowledge challenges, and collaborative capacity builders in network settings. Public Administration Review, 68(2), 334-349.

Welch, D., Swaffield, J., \& Evans, D. (2018). Who's responsible for food waste? Consumers, retailers and the food waste discourse coalition in the United Kingdom. Journal of Consumer Culture. https://doi. org/10.1177/1469540518773801.

Xue, L., Liu, G., Parfitt, J., Liu, X., Van Herpen, E., Stenmarck, Å., et al. (2017). Missing food, missing data? A critical review of global food losses and food waste data. Environmental Science and Technology, 51(12), 6618-6633.

Open Access This chapter is licensed under the terms of the Creative Commons Attribution 4.0 International License (http://creativecommons. org/licenses/by/4.0/), which permits use, sharing, adaptation, distribution and reproduction in any medium or format, as long as you give appropriate credit to the original author(s) and the source, provide a link to the Creative Commons license and indicate if changes were made.

The images or other third party material in this chapter are included in the chapter's Creative Commons license, unless indicated otherwise in a credit line to the material. If material is not included in the chapter's Creative Commons license and your intended use is not permitted by statutory regulation or exceeds the permitted use, you will need to obtain permission directly from the copyright holder.

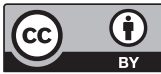

